\title{
Diretrizes Políticas Globais E RelaÇões Políticas Locais: POSSÍVEIS INDÍCIOS DA “GESTÃO-VAGALUME”
}

\author{
Global Policy Guidelines and local Political Relations: \\ POSSIBLE INDICATIONS OF "FIREFLY MANAGEMENT"
}

\begin{abstract}
Arthur Medrado Soares Araujo Doutorando no PPGCine/UFF, Mestre em educação e Bacharel em jornalismo pela UFOP. Atuou como editor, roteirista e diretor na Série educacional Mosaico, analisada neste artigo. Coordena as atividades da Olhares (Im)Possíveis em Ouro Preto, Minas Gerais, Brasil arthurmedrado@gmail.com
\end{abstract}

Resumo: Nestes escritos analisa-se os conceitos apresentados por Stephenf J. Ball (2001) no texto Diretrizes Políticas Globais e Relações Políticas Locais em Educação, bem como o relato de experiência de três professoras/gestoras da educação pública de Minas Gerais no que tange à relação dessas "atrizes sociais" com ações educativas e suas práticas no campo da gestão educacional. A tentativa foi encontrar os atravessamentos entre a literatura e a prática no testemunho dos sujeitos que estão no "chão da escola". Para isso, foram utilizadas entrevistas com as professoras para a série educacional Mosaico, produzida pela Escola de Gestores do CEAD/UFOP, na intenção de buscar conexões e afastamentos do texto de Ball, além de possíveis "causas" para denominar essas mulheres como "vagalumes" (HUBERMAN, 2011).

Palavras-chaves: Gestão escolar. Política. Entrevistas. Realidade escolar.

Abstract: These writings intend to analyze the concepts presented by Stephenf J. Ball (2001) in the text Global Policy Guidelines and Local Political Relations in Education in relation to the experience report of three teachers of public education in Minas Gerais regarding the relation of these "social actresses" with educational actions and their practices in the field of educational management. The attempt, then, is to find the crossings between literature and practice in the testimony of the subjects who are on the "school floor". In order to do so, we used interviews with teachers for the Mosaic Educational Series, produced by the CEAD / UFOP School of Managers, with the intention of seeking connections and removals from the text of Ball and the possible "causes" to denominate these women as "fireflies" (HUBERMAN , 2011).

Keywords: School management. Politics. Interviews. School reality.

\section{Introdução}

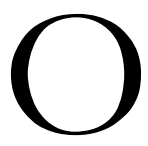

Artigo de Stephen J. Ball é um importante instrumento para pensarmos as interfaces e distanciamentos entre políticas educacionais e sua aplicação no âmbito local, ou seja, no micro. O autor apresenta um conjunto de problemáticas e questões conceituais para exemplificar um novo paradigma de políticas educacionais no terreno das discussões em torno da globalização, da convergência de políticas (DOLOWUTZ et al. apud BALL, 2001), da performatividade e da gestão. 
O novo paradigma nos apresenta uma questão relevante para a reflexão no âmbito das discussões em educação, visto que, para o autor, dentre as tendências educacionais modernas há um abandono dos propósitos educacionais em detrimento das questões de mercado. Nesse novo cenário, por meio dos "empréstimos de políticas", as políticas educativas se confundem com as políticas econômicas e a educação se apresenta diretamente afetada por elas. O que resta para a escola são as "prescrições e assunções normativas do economicismo e o tipo de cultura na qual a escola existe e pode existir é articulado dentro dessa lógica” (LINGARD, LADWIG \& LUKE apud BALL, 2001, p. 100).

Diante dessa breve explicação, é importante esclarecer que a ideia neste artigo é levantar uma discussão sobre o papel do gestor em educação na aplicação das políticas educativas no âmbito local. Tentou-se observar como o desejo e o impulso desse ator social podem, inclusive, a nível micro, modificar e subverter as lógicas das políticas para novamente localizar a escola como espaço fomentador dos princípios educativos da libertação e emancipação. A hipótese é a de que em uma análise mais subjetiva das políticas públicas os gestores, por meio de suas ações, possam ser entendidos como sujeitos-vagalume ${ }^{11}$ no processo de aplicação das políticas públicas. Ou seja: identificar o/a gestor/a em educação como um ser micro político de resistência. Antes de adentrarmos nessa discussão, no entanto, é necessário apresentar alguns conceitos fundamentais de Ball (2001).

\section{Dos conceitos presentes na literatura}

\subsection{Globalização}

A ideia fundamental do conceito de globalização consiste na questão do futuro do Estado nacional como entidade cultural e política. Essa ideia é articulada por meio de quatro perspectivas fundamentalmente relacionadas: econômica, política, cultural e social. As transformações econômicas e políticas, pensando os dois primeiros aspectos, nos apresentam como ponto central o contexto das transformações econômicas globais dos Estados-nação individuais e como os mesmos mantêm a capacidade de conduzir e gerenciar suas economias diante das corporações multinacionais desenraizadas. Desse modo, o fluxo e o influxo do mercado financeiro global dialogam e se confrontam com e para a produção industrial moderna. Ball levanta ainda outra questão importante: é possível que os Estados-nação percam sua autonomia política diante das organizações supranacionais? O próprio autor vai 
dizer que "existe a possibilidade de que nenhum Estado possua, de fato, o controle sobre sua nação!" (BALL, 2001, p. 101).

No que tange ao aspecto cultural, a questão central gira em torno da influência dos efeitos de unificação que o processo de globalização gera. A exacerbada ocidentalização e americanização do mundo produzem um consumidor genérico. Diante de um cenário como esse, o autor faz uma provocação: “[...] será que estamos a viver a criação de um "MacMundo", conduzido pelos interesses das indústriais culturais globais e disseminado pela mídia-global - televisão, cinema e internet?” (BALL, 2001, p. 101). Essa visão presente no texto, quase apocalíptica, pode ser superada na atuação do gestor na aplicação da política no âmbito local, tema que tratarei mais adiante neste texto.

Do ponto de vista social, questiona-se: “terá a natureza da experiência social pessoal sido alterada fundamentalmente diante da compressão espaço-tempo da globalização (BALL, 2001, p. 101)? O autor recorre a Anthony Giddens para afirmar que a tessitura do cotidiano não acontece "lá fora" (GIDDENS apud BALL, 2001, p. 101), não é algo distante. O que essa localização provoca é uma alteração de espaço-tempo que torna a vida mais volátil e os conteúdos do dia a dia mais efêmeros. A produção de mercadorias apresenta-se sob valores como o instantâneo e o descartável. Além disso, esse aspecto contribui para uma "crise de representação". Ball afirma que isso "constitui, em parte, aquilo que Pfeil (1998, p. 386) chama de 'estrutura de sentimento pós-moderno' e evita 'o terror da contingência a partir da qual toda a possibilidade de significância expressiva é eliminada"” (BALL, 2001, p. 101-102).

\subsection{Gestão}

Para Ball (2001), a gestão apresenta uma nova forma de poder no setor público. Nesse sentido, o gestor, nos últimos vinte anos, atua não somente na reforma política como também rearranja culturalmente o setor público em diversos países do $\mathrm{Norte}^{22}$. A atuação do gestor remodela as relações de poder e é decisiva ao definir como e onde as escolhas sobre as políticas sociais serão feitas (CLARKE, COCHRANE, MCLOUGHLIN apud BALL, 2001, p. 108). Nas palavras do autor:

A gestão representa a introdução de um novo modelo de poder no setor público; é uma "força transformadora". Ela desempenha um papel crucial no desgaste dos regimes ético-profissionais nas escolhas e a sua substituição por regimes empresariais e competitivos. Enquanto os mercados trabalham de fora para 
dentro, a gestão funciona de dentro para fora. O gestor é o herói cultural do novo paradigma (BALL, 2001, p. 108).

O trabalho desse herói, ou heroína, inclui um mergulho que penetra ações e culturas. Essa infusão resulta, segundo o autor, num sentimento de responsabilização e comprometimento (processos que acontecem simultaneamente) dos sujeitos envolvidos e comprometidos nas organizações. Por isso essas novas pedagogias invisíveis de gestão abrem espaço para um maior controle daquilo que é gerido. Nesse sentido, “o enquadramento menos rígido do novo gerenciamento permite que um maior leque de comportamentos dos trabalhadores se torne público; este é "o bloqueio disfarçado da solidariedade mecânica"” (BALL, 2001, p.109).

Fundem-se, então, o ato de ensino e a subjetividade dos/as professores/as. Isso modifica a forma de se relacionar, no contexto da qualidade e excelência, e as novas formas de controle empresarial (que se apresentam por meio da competição e do marketing). Os resultados dessa operação são aparentemente conflituosos: o aumento da individualização e a geração de uma "comunidade". O primeiro efeito inclui o abandono das solidariedades baseadas numa identidade profissional comum, nas novas formas de filiações institucionais e sindicais. Já o segundo envolve o compromisso individual e as ações da organização.

Ball afirma que por meio do fomento de uma "cultura empresarial" os gestores se posicionam como delineadores, instrumentalizadores e normatizadores de um modo de lidar com os outros sujeitos envolvidos, na tentativa de alcançar os fins desejáveis (BALL, 2001). Esse posicionamento, no entanto, gera novamente resultados paradoxais: na mesma medida em que "representam um afastamento dos métodos de controle", que tomam como base uma postura de desconfiança (ou pouco confiança, nas palavras do autor) para com os outros sujeitos envolvidos, também entram em cena novas formas e práticas de vigilância e automonitoramento. Valoriza-se, pois, a resolução de problemas na mesma medida em que há uma supervalorização dos sistemas de avaliação, alcance dos objetivos e comparação de resultados.

É por meio dessa "microdisciplina" que a gestão pode trazer para o setor público referências e práticas que antes estavam localizadas apenas na cultura empresarial. Nessas novas óticas as instituições do setor público acabam reiterando a grande narrativa ideológica do sistema capitalista, utilizando estratégias que antes eram empregadas apenas pelas 
empresas. Nesse sentido, e por assumirem qualidades específicas do "capitalismo rápido", há também um culto excessivo à performatividade.

\subsection{Performatividade}

Ball (2001) apresenta a performatividade, baseado também nas colocações do filósofo francês Jean-François Lyotard, como um instrumento cultural que em seu sistema instaura o terror, realiza julgamentos e faz comparações. Nessa lógica, o desempenho funciona como medida de resultado e produtividade. Representa e resume, portanto, o valor de um sujeito ou organização no campo de avaliação: “estabelece-se [...] uma equação entre riqueza, eficiência e verdade" (LYOTARD apud BALL, 2001, p. 109).

Dá-se menos importância às questões espaço-temporais para priorizar as formas de controle que se configuram na base de dados, reunião para avaliação, balanços importantes, inspeções e avaliações. Ou seja: há um afastamento cada vez mais intenso de critérios e perspectivas subjetivas para o culto, fomento e fixação dos critérios objetivos. O surgimento desse culto ao desempenho, da performance, se dá pelo afastamento da possível certeza de ser vigiado; ele acontece numa nova configuração: na incerteza e na instabilidade de ser avaliado de diferentes maneiras, por diferentes e distintos meios. Esse fluxo de exigências coloca os sujeitos num constante estado de alerta, visto que as expectativas e indicadores acabam localizando-os num terreno de constante sentimento de vigília e responsabilização. Nessa esfera localizada por Ball, quem está em cheque é o sujeito: frequentemente ancorado no princípio da inevitabilidade, da insegurança e da incerteza.

Nesse sentido, pensando no professor, podemos pensar a performatividade inclusive como uma das causadoras do mal-estar docente (DINIZ, 2011) ${ }^{33}$. O que isso gera no ceio da escola pública? Sujeitos operando constantemente no "complexo leque" de cifras e indicadores de desempenho. O cenário é de total incerteza, propósitos contraditórios, motivações vagas e autoestima instável:

O fato de que existem dúvidas constantes sobre quais juízos de valor podem ocorrer a qualquer momento implica que toda e qualquer comparação deve ser levada em conta, "o que assegura o funcionamento automático do poder" (Foucault, 1977, p. 201), na intersecção da formação do governo, da organização e do eu. Tudo isto tem uma dimensão social e interpessoal. As disciplinas do desempenho inserem-se num complexo institucional, relações de equipe, grupo e 
comunais (por exemplo, a comunidade acadêmica, a escola, os departamentos, a universidade) (Ball, 2000b) (BALL, 2001, p. 110).

$\mathrm{Na}$ teia das relações entre gestão, mercado e performatividade ocorrem implicações de ordens diversas, que afetam a escola tanto nas relações pessoais como nas funcionais (e esse processo ocorre de forma vertical, mas também horizontal). É importante considerar ainda que "as relações profissionais tornam-se individualizadas à medida que as oportunidades para o discurso comunitário e profissional diminuem" (SEDDON apud BALL, 2001, p 110). Aumenta-se o trabalho burocrático, os sistemas de manutenção, a produção de relatórios, a vigilância sobre o trabalho docente e sobre os produtos finais da educação (BALL 2001). Entretanto, será que a performatividade poderia operar em alguns sujeitos no sentido de gerar atitudes de resistência e provocá-los em relação a mudanças sociais nas suas comunidades, ainda que no geral pareça que a estrutura do sistema provoque apenas o contrário?

\section{Do testemunho das professoras}

Para este artigo foram analisadas as entrevistas realizadas com professoras para a série educacional Mosaico, produzida durante os anos de 2015 e 2016 pela Escola de Gestores, do Centro de Educação a Distância (CEAD), da Universidade Feral de Ouro Preto (UFOP). A série tem como objetivo principal a difusão de conteúdos temáticos fundamentais para a reflexão sobre a gestão escolar democrática de maneira acessível e dinâmica, por meio de um canal no YouTube 44. $^{2}$

Cada episódio da série possui duração média de dez minutos e traz uma convidada para expor e esclarecer questões sobre a temática em questão. Temas como gestão escolar democrática, violência e indisciplina, a relação entre família e escola, história das instituições escolares, diversidade e inclusão, práticas pedagógicas, entre outros, foram abordados pelas professoras convidadas. Além dos vídeos, cada entrevista está disponível na íntegra em uma página do soundcloud ${ }^{55}$.

No processo de produção da série realizamos entrevistas com 6 professoras, porém, para essa análise foram utilizadas as falas de três delas. Marisa Bueno e Sônia Ferreira, professoras da rede municipal de ensino, relataram suas vivências em relação à "Experiência com a gestão escolar" e à "Violência e indisciplina", respectivamente. A terceira fala analisada foi da professora da Universidade do Estado de Minas Gerais (UEMG) Welessandra Benfica, 
a qual também tem experiência com a escola e abordou a "Coordenação e práticas educativas na escola".

Percebo que a fala das professoras se aproximam em muitos pontos das questões apresentadas no texto de Ball, principalmente no que tange à questão da performatividade. Nesse sentido, muitas falas se repetem, como as de Sônia, que define a escola como um lugar de "dinâmica intensa", cheia de questões e demandas. O bom senso, para ela, deve ser um exercício permanente, pois tomar decisões como gestora esbarra em outros terrenos, como a violência, "a questão dos pais, dos recursos" há "pressão de cima e de baixo"”77.

Ao mesmo tempo fica claro que, pelo menos no caso das gestoras entrevistadas, há sempre um impulso de localizar a escola na sua missão: "ter o tempo todo em mente quem está em primeiro lugar; o aluno é a razão de ser da escola" ${ }^{\text {, }}$, afirma Marisa. Essa fala demonstra que se está indo na contramão dos empréstimos de políticas, das demandas e dinâmicas da globalização. É possível afirmar, portanto, que existem exceções na aplicação das políticas que não permitem o "crescente abandono ou marginalização dos propósitos sociais da educação" apontados por Ball.

Marisa reconhece que há situações em que o gestor acaba inviabilizado de dar conta de todas as questões, e é impossível, inclusive estruturalmente, se posicionar como sujeito em todas as situações, já que "tem coisas que você acredita e não dá para ser e tem coisas que você não acredita e tem que ser, porque é um espaço público" "99. Mesmo assim, afirma Marisa, "é impossível que eu guarde a Marisa em casa, não dá para ser tão objetiva assim"1010. Acredito que esses trechos demonstram o grande dilema e as tensões presentes nas relações globais e locais. "Nem sempre a demanda da população é a demanda do seu patrão"1111, aponta a professora.

Os apontamentos de Marisa nos dão outra pista interessante sobre os aspectos presentes no texto de Ball, já que a gestora entrevistada parece saber a importância dada ao gestor como ator social no processo, ideia também colocada por Ball. Ela afirma:

O diretor é o recheio do sanduiche. Quando você pensa o Estado numa ponta e a escola em outra, o diretor é aquele indivíduo que faz uma interlocução do que se tem de lei, de recursos, do que se tem enquanto Estado para a população. Mas que também precisa escolher o que essa população tem e de certa forma traduzir, cobrar, colocar em prática, reclamar do Estado ${ }^{1212}$.

A questão da "glocalização" (BALL, 2001) também aparece em alguns momentos das entrevistas realizadas. Welessandra, por exemplo, fala da importância de conhecer e 
MEDRADO, Arthur.

engajar a escola, a comunidade escolar e as equipes: "é importante conhecer a equipe; a escola é igual em qualquer lugar, mas diferente naquilo que a compõe"1313.

Vale ressaltar que a questão da performance e seus mecanismos de controle inevitavelmente aparecem na fala das entrevistadas: "vai se tornando gestor na medida em que ele começa a se sentir bem com o que faz, porque o início de uma gestão é muito tensa, a gente se sente muito pressionado", afirma a professora Marisa.

\section{Considerações finais}

A partir do que foi apresentado tanto por Ball quanto pelo testemunho das professoras, podemos pensar os "gestores-heróis" como aqueles vaga-lumes que tanto foram mencionados por Pasolini e Giorgio Agamben: seres luminescentes, intocáveis e resistentes. Luminescentes por serem movidos por um impulso de transformação, de possíveis melhorias. Intocáveis por se libertarem durante a ação, no sentido de buscar como finalidade o melhor para a escola e a comunidade escolar, muitas vezes atuando nas brechas do Estado, das políticas públicas.

Sobrevivência dos vaga-lumes, de Didi-Huberman (2011), é um livro que atravessa vários campos de pensamento em uma leitura inspirada por um conjunto de escritores, artistas e filósofos ${ }^{1414}$. Caminho pelos conceitos que fazem com que o autor defenda a importância do sublime das imagens e dos atos de resistência criados na sociedade contemporânea. Nesse caso, interessa particularmente a negação de uma perspectiva apocalíptica, ou melhor, a discordância com autores ${ }^{1515}$ que apresentam a destruição dos vaga-lumes ${ }^{1616}$.

Cientificamente o vaga-lume é um inseto coleóptero que possui emissões luminosas. Tais emissões acontecem devido aos órgãos fosforescentes localizados na parte inferior do abdômen. Sua luz surge de uma reação química. Cerca de 95\% aproximadamente da energia produzida transforma-se em luz e somente 5\% se transforma em calor. Quem comanda essa reação é ele mesmo, o vagalume, já que o tecido que emite a luz é ligado na traqueia e no cérebro. Infelizmente, os vaga-lumes estão ameaçados pela forte iluminação da contemporaneidade, pois, quando entram em contato com ela, sua bioluminescência é anulada, o que interfere fortemente na reprodução e os coloca em risco de extinção.

Vale falar aqui do vagalume que encontrei em Didi-Huberman (2011), metáfora para tratar da diferenciação entre dois mundos e nos localizar "entre eles", não em apenas um deles. De um lado, o mundo sitiado por imagens, iluminado pelos holofotes midiáticos que iluminam muito, mas com informações consensuais e luzes estagnantes. A luz dos refletores, "muito ferozes, olhos mecânicos aos quais era impossível escapar" (DIDI-HUBERMAN, 2011, p.155). Do outro, o mundo de quem habita as margens, extenso e iluminado por luzes 
fugazes, onde "povos vaga-lumes buscam como podem sua liberdade de movimento, fogem dos projetores do reino, fazem o impossível para afirmar seus desejos, emitir seus próprios lampejos e dirigi-los a outros" (DIDI-HUBERMAN, 2011, p.155). Os povos-vagalume, aqui o gestor-vagalume, nos ajudam a enxergar a invisibilidade de quem não é visto e acaba anulado pelas luzes dos refletores (que aqui podemos pensar como as leis e políticas públicas, a educação bancária, o quase-mercado etc.).

O vaga-lume denuncia e nos faz ver a crueldade das luzes que vigiam, que homogeneízam e inviabilizam as ações de quem pretende tornar o mundo um cenário mais transparente e consensual, por meio de ações que parecem inofensivas. "Os resistentes de todos os tipos, ativos ou passivos, se transformam em vaga-lumes fugidios tentando se fazer tão discretos quanto possível, continuando ao mesmo tempo a emitir seus sinais" (DIDIHUBERMAN, 2011, p. 17).

Compartilho das ideias Huberman (2011) por entendê-las como mais adequadas para encontrar uma possível relação com os sujeitos dentro destes escritos. De uma forma mais específica, proponho promover a relação de aproximação do vagalume com a figura do gestor no que tange a essas "imagens e atos de resistência". Mais especificamente no que diz respeito à questão do "Saber vagalume": quebrando, por exemplo, com a própria etimologia da palavra aluno (sem luz). "Eu odeio a palavra aluno"1717, afirma a professora Welessandra. O vagalume nesse sentido seria capaz de "ser maior" que o mundo sitiado pela luz dos refletores.

Para finalizar, retomo a pergunta feita por Didi-Huberman (2011): seria possível encontrar "os meios de ver aparecerem os vaga-lumes no espaço de superexposição, feroz, demasiado luminoso, de nossa história presente" (DIDI-HUBERMAN, 2011, p. 70)? O autor afirma que seria preciso apreender e analisar as "linguagens do povo, gestos, rostos, tudo isso que, por contraste, desenha zonas ou redes de sobrevivências no lugar mesmo onde se declaram sua extraterritorialidade, sua marginalização, sua resistência, sua vocação para a revolta” (DIDI-HUBERMAN, 2011, p. 72). O vagalume é o encontro das duas luzes. São os que resistem, fazendo-se parecer tão discretos enquanto continuam emitindo seus sinais por meio de sua atuação.

Notas:

\footnotetext{
${ }^{1}$ Vagalume se refere a uma ideia de Didi-Huberman (2011) que esclarecerei melhor mais adiante.

${ }^{2} \mathrm{E}$ ainda que nosso país esteja no Sul, é possível perceber as aproximações dos "modos operantes", visto que estamos percebendo, identificando e presenciando o processo de globalização.
} 
3 Ver: DINIZ, M.; SANTOS, E. H. O sujeito, o saber e as práticas educativas. Trabalho e Educação, Belo Horizonte, v. 12, p. 137-150, jan. 2003. Disponível em: $<$ http://www.portal.fae.ufmg.br/seer/index.php/trabedu/article/view/1237/999>. Acesso em: 12 Mar. 2017.

${ }^{4}$ Disponível em: http://migre.me/whkh8.

${ }^{5}$ Diponível em: http://migre.me/whkp0.

${ }^{6}$ FERREIRA, S. C. Ouro Preto, 17 março. 2016. Entrevista a Série educacional Mosaico. Disponível em: http://migre.me/whkh8.

${ }^{7}$ BUENO, M. Ouro Preto, 25 Fevereiro. 2016. Entrevista a Série educacional Mosaico. Disponível em: http://migre.me/whkh8.

${ }^{8}$ BUENO, M. Ouro Preto, 25 Fevereiro. 2016. Entrevista a Série educacional Mosaico. Disponível em: http://migre.me/whkh8.

${ }_{9}^{9}$ BUENO, M. Ouro Preto, 25 Fevereiro. 2016. Entrevista a Série educacional Mosaico. Disponível em: http://migre.me/whkh8

${ }^{10}$ BUENO, M. Ouro Preto, 25 Fevereiro. 2016. Entrevista a Série educacional Mosaico. Disponível em: http://migre.me/whkh8.

${ }^{11}$ BUENO, M. Ouro Preto, 25 Fevereiro. 2016. Entrevista a Série educacional Mosaico. Disponível em: http://migre.me/whkh8.

${ }_{12}$ Disponível em: http://migre.me/whkh8.

13 BENFICA, W. Ouro Preto, 14 Julho. 2016. Entrevista a Série educacional Mosaico. Disponível em: http://migre.me/whkh8.

${ }^{14}$ É na perspectiva desse historiador da arte que começo a pensar a relação "da luz de refletores", que pode ser entendida como a ausência da experiência ao fim do dia, com a "luz sublime", que na perspectiva de autores como Pasolini, estaria perdida na sociedade contemporânea.

${ }^{15}$ Como: Pasolini, Benjamin, Bataille, Agamben e Arendt.

${ }^{16}$ Apresentados pelo autor como único ser que carrega a luz sublime na sociedade.

${ }^{17}$ BENFICA, W. Ouro Preto, 14 Julho. 2016. Entrevista a Série educacional Mosaico. Disponível em: http://migre.me/whkh8.

\section{Referências}

BALL, S. Diretrizes Politicas Globais e Relações Politicas Locais em Educação. Currículo Sem Fronteiras, v. 1, n. 2, p.99-116, Jul/Dez 2001.

BERNSTEIN, B. (1971). On the Classification and Framing of Educational Knowledge. In M. F. D. Young (Ed.), Knowledge and Control, . London: Collier-Macmillan.

CLARKE, J.; COCHRANE, A.; MCLAUGHLIN, E. Managing Social Policy. London: Sage, 1994.

DIDI-HUBERMAN, G. Sobrevivência dos vaga-lumes. Belo Horizonte: Editora UFMG, 2011.

DINIZ, M.; SANTOS, E. H. O sujeito, o saber e as práticas educativas. Trabalho e

Educação, Belo Horizonte, v. 12, p. 137-150, jan. 2003. Disponível em:

<http://www.portal.fae.ufmg.br/seer/index.php/trabedu/article/view/1237/999>.

Acesso em: 12 Mar. 2017.

DOLOWITZ, D. P., HULME, R., NELLIS, M., \& O’NEILL, F. (2000). Policy Transfer and British Social Policy: Learning from the US A? Buckingham: Open University Press, 2000.

GIDDENS, A. (1994). Beyond Left and Right: the Future of Radical Politics. Cambridge: Polity Press.

HARVEY, D. (1989). The Condition of Postmodernity. Oxford: Basil Blackwell. 
LINGARD, B., LADWIG, J., \& LUKE, A. School Effects in Postmodern Conditions. In R. Slee, G. Weiner, with, \& S. Tomlinson (Eds.), School Effectiveness for Whom? Challenges to the School Effectiveness and School Improvement Movements. London: Falmer, 1998.

LYOTARD, J.-F. The Postmodern Condition: A Report on Knowledge. (Vol. 10). Manchester: Manchester University Press, 1984.

MOS AICO - Coordenação e práticas educativas na escola - Profa. Welessandra Benfica (Parte 1). Direção de Arthur Medrado Soares Araujo. Realização de Cead(ufop). Coordenação de Breynner Ricardo de Oliveira. Roteiro: Arthur Medrado Soares Araujo. Ouro Preto: Escola de Gestores, 2016. 9 vídeos (9 min.), Digital, son., color. Série Mosaico. Disponível em: \&lt;http://migre.me/whkUb\&gt;. Acesso em: 20 mar.2017.

MOS AICO - Coordenação e práticas educativas na escola - Profa. Welessandra Benfica (Parte 2). Direção de Arthur Medrado Soares Araujo. Realização de Cead(ufop). Coordenação de Breynner Ricardo de Oliveira. Roteiro: Arthur Medrado Soares Araujo. Ouro Preto: Escola de Gestores, 2016. 9 vídeos (9 min.), Digital, son., color. Série Mosaico. Disponível em: \&lt;http://migre.me/whkV4\&gt;. Acesso em: 20 mar.2017.

MOS AICO - Experiência com a gestão - Profa Marisa Bueno. Direção de Arthur Medrado Soares Araujo. Realização de Cead(ufop). Coordenação de Breynner Ricardo de Oliveira. Roteiro: Arthur Medrado Soares Araujo. Ouro Preto: Escola de Gestores, 2016. 9 vídeos (9 min.), Digital, son., color. Série Mosaico. Disponível em: \&lt;http://migre.me/whkQv\&gt;. Acesso em: 20 mar. 2017.

MOS AICO - Violência e Indisciplina - Profa. Sônia Carolina Ferreira. Direção de Arthur Medrado Soares Araujo. Realização de Cead(ufop). Coordenação de Breynner Ricardo de Oliveira. Roteiro: Arthur Medrado Soares Araujo. Ouro Preto: Escola de Gestores, 2016. 9 vídeos (9 min.), Digital, son., color. Série Mosaico. Disponível em: http://migre.me/whkXk\&gt;. Acesso em: 20 mar. 2017.

PFEIL, F. (1988). Postmodernism as a 'structure of feeling'. In L. Grossberg \& C. Nelson (Eds.), Marxism and the Interpretation of Culture, . London: Macmillan.

SEDDON, T. Education: Deprofessionalised? Or Reregulated, Reorganised and Reauthorised? In S. J. Ball (Ed.), Sociology of Education: Major themes. Volume IV Politics and Policies, . London: RoutledgeFalmer, 2000

Recebido em 01 fev. 2019 / Aprovado em 29 out. 2019

\section{Para referenciar este texto}

MEDRADO, Arthur. Diretrizes políticas Globais e Relações Políticas Locais: possíveis indícios da "gestão-vagalume". Cadernos de Pós-graduacão, São Paulo, v. 18, n. 2, p. 138-148, jul./dez. 2019.

Disponível em: $<\underline{\text { https://doi.org/10.5585/cpg.v18n2.11479>. }}$. 